University of South Florida

DIGITAL COMMONS

Digital Commons @ University of

@ UNIVERSITY OF SOUTH FLORIDA

South Florida

8-1-2012

\title{
Dha Derivatives of Fish Oil as Dietary Supplements: a Nutrition- Based Drug Discovery Approach for Therapies to Prevent Metabolic Cardiotoxicity
}

\author{
Yonggang $\mathrm{Ma}$ \\ University of Texas at San Antonio \\ Merry L. Lindsey \\ University of Texas at San Antonio \\ Ganesh V. Halade \\ University of Texas at San Antonio, ghalade@usf.edu
}

Follow this and additional works at: https://digitalcommons.usf.edu/intmed_facpub

\section{Scholar Commons Citation}

Ma, Yonggang; Lindsey, Merry L.; and Halade, Ganesh V., "Dha Derivatives of Fish Oil as Dietary Supplements: a Nutrition-Based Drug Discovery Approach for Therapies to Prevent Metabolic Cardiotoxicity" (2012). Internal Medicine Faculty Publications. 64.

https://digitalcommons.usf.edu/intmed_facpub/64

This Review is brought to you for free and open access by the Internal Medicine at Digital Commons @ University of South Florida. It has been accepted for inclusion in Internal Medicine Faculty Publications by an authorized administrator of Digital Commons @ University of South Florida. For more information, please contact digitalcommons@usf.edu. 


\title{
DHA derivatives of fish oil as dietary supplements: a nutrition- based drug discovery approach for therapies to prevent metabolic cardiotoxicity
}

\author{
Yonggang Ma, PhD, Merry L. Lindsey, PhD, and Ganesh V. Halade, $\mathrm{PhD}^{\dagger}$ \\ The University of Texas Health Science Center at San Antonio, Division of Geriatrics, \\ Gerontology and Palliative Medicine, Department of Medicine, San Antonio, TX, USA
}

\begin{abstract}
Introduction-During the early 1970s, Danish physicians Jorn Dyerberg and colleagues observed that Greenland Eskimos consuming fatty fishes exhibited low incidences of heart disease. Fish oil is now one of the most commonly consumed dietary supplements. In 2004, concentrated fish oil was approved as a drug by the FDA for the treatment of hyperlipidemia. Fish oil contains two major omega-3 fatty acids: eicosapentaenoic acid (EPA) and docosahexaenoic acid (DHA). With advancements in lipid concentration and purification techniques, EPA- or DHA-enriched products are now commercially available, and the availability of these components in isolation allows their individual effects to be examined. Newly synthesized derivatives and endogenously discovered metabolites of DHA exhibit therapeutic utility for obesity, metabolic syndrome and cardiovascular disease.
\end{abstract}

Areas covered-This review summarizes our current knowledge on the distinct effects of EPA and DHA to prevent metabolic syndrome and reduce cardiotoxicity risk. Since EPA is an integral component of fish oil, we will briefly review EPA effects, but our main theme will be to summarize effects of the DHA derivatives that are available today. We focus on using nutritionbased drug discovery to explore the potential of DHA derivatives for the treatment of obesity, metabolic syndrome and cardiovascular diseases.

Expert opinion-The safety and efficacy evaluation of DHA derivatives will provide novel biomolecules for the drug discovery arsenal. Novel nutritional-based drug discoveries of DHA derivatives or metabolites may provide realistic and alternative strategies for the treatment of metabolic and cardiovascular disease.

\section{Keywords}

cardiovascular disease; dietary supplement; docosahexaenoic acid; eicosapentaenoic acid; fish oil; metabolic syndrome; obesity

\footnotetext{
(C) 2012 Informa UK, Ltd.

${ }^{\dagger}$ Author for correspondence: The University of Texas Health Science Center at San Antonio, San Antonio Cardiovascular Proteomics Center, Barshop Institute of Longevity and Aging Studies, and Division of Geriatrics, Gerontology and Palliative Medicine, Department of Medicine, 15355 Lambda Drive, MC 7755, San Antonio, TX 78245, USA, Tel: +1 2105625032 ; Fax: +1 210 562 5032; halade@uthscsa.edu.

Declaration of interest

ML Lindsey was supported by National Institutes of Health (NIH) grants NHLBI HHSN 268201000036C (N01-HV-00244), provided to the San Antonio Cardiovascular Proteomics Center, and R01 HL-075360. ML Lindsey was also supported by the Max and Minnie Tomerlin Voelcker Fund, and the Veteran's Administration (Merit). GV Halade received financial support, in the form of a grant, from the NIH-National Center for Complementary and Alternative Medicine(NIH 1K99AT006704-01). Y Ma declares no conflict of interest and has received no payment in the preparation of this manuscript.
} 


\section{Introduction}

In the 1970s, Danish physicians described the plasma lipid and lipoprotein patterns of Eskimos living on the west coast of Greenland and compared their diet with that only typical for the Danish population [1]. Two of these physicians, Dyerberg and Bang, further determined that blood obtained from Eskimos had a nearly twofold longer clotting time than blood from Danes, and that this difference in clotting time positively correlated to the low mortality from coronary heart disease among the Eskimos, compared with rates for the Danes. Moreover, platelets isolated from Eskimos showed reduced aggregability following exposure to adenosine diphosphate and collagen, compared with platelets isolated from Danes [2]. Since the percentages of dietary fat intake was similar between Greenland Eskimos and Danes, but lipid profiling indicated reduced concentration of linoleic acid in Eskimos, a theory developed that the striking difference in coronary heart disease could be due to the large difference in the intake of marine fats in Eskimos [3]. This was the beginning of the past 40 years of research on fish oil effects on human health.

Omega-3 fatty acids are n-3 long chain polyunsaturated fatty acids (LC-PUFA). The two major n-3 LC-PUFAs are eicosapentaenoic acid (EPA; 20:5n-3) and docosahexaenoic acid (DHA; 22:6n-3), and both are found in marine fish oils and have been found to be effective for the treatment of hyperlipidemia in mice and rats [4,5] as well as in humans [6,7]. While the majority of studies have focused on cardiovascular effects, fish oil has also been shown to be effective for the treatment of lupus, kidney disease [8], osteoporosis [9] and macular degeneration [10].

The Gruppo Italiano per lo Studio della Sopravvivenza nell'Infarto miocardico (GISSI) Prevenzione trial established that omega-3 dietary supplementation $(1 \mathrm{~g} / \mathrm{d})$ reduced the risk of cardiovascular death by $45 \%$ in a patient population of $>2000$ patients, all of whom had experienced a previous myocardial infarction [11]. Of note, a diet rich in omega-3 fatty acids is currently recommended by the American Heart Association (http://

www.americanheart.org, accessed on 16 Jan 2012). A wide range of research has shown that fish oil reduces the risk of major cardiovascular events, including myocardial infarction, sudden cardiac death, coronary heart disease, atrial fibrillation and death in patients with heart failure [12-15]. By contrast, a recent meta-analysis performed by Kwak et al. concluded that there was insufficient evidence to indicate a secondary preventive effect of omega-3 fatty acid supplements against overall cardiovascular events among patients with a history of cardiovascular disease [16]. Fish oil has anti-inflammatory and anti-arrhythmic effects, as well as improves endothelial cell and platelet functions $[17,18]$.

The National Health and Nutrition Examination Survey (NHNES) first pointed out an alarming prevalence of obesity in the 1990s, and this prevalence has continued to be high for the last decade (1999 - 2010) [19]. Obesity is defined as a body mass index of 30 or greater (calculated as weight in kilograms divided by height in meters squared). One in every three adults and one in every six children in the US is obese [19], and obesity is the most robust risk factor for the development of type 2 diabetes [20]. Gonzalez-Periz established that omega-3 fatty acids protect against obesity-induced inflammation. Omega-3 fatty acids increase synthesis of the bioactive lipid mediators protectin D1 and resolvin D1 and decrease the synthesis of the omega-6-derived eicosanoids cyclooxygenase, prostaglandins and lipoxygenase in adipose tissue, despite having no effect on body weight. Additionally, omega-3 fed mice show increased adipose tissue mRNA expression of genes known to be protective against systemic insulin resistance, including adiponectin, peroxisome proliferator-activated receptor $\gamma$ and insulin-receptor substrate-1 [21]. 
While a large amount of research has been performed to understand the role of fish oil on many biological processes, focused research is needed to dissect the relative and differential cardioprotective effects of consuming EPA or DHA, as well as their derivatives and metabolites. A major concern with fish oil research has been the lack of consistency in results. This variability is due in large part to differences among studies in dosage, duration, population target, sample size, assay methods and selection of control or placebo, as well as differences in the relative concentration of EPA and DHA used in the different supplements tested. Most studies do not determine the concentration of EPA and DHA in plasma or serum samples, which makes it difficult to normalize studies based on bioavailability. Comparative studies focused on the independent effects of EPA and DHA on various cardiovascular outcomes, particularly in metabolic syndrome, are needed.

In this review article, we will discuss the comparative effects of EPA and DHA present in fish oil and future directives with particular emphasis on DHA derivatives. We will also summarize the current literature on fish oil effects on cardiovascular disease, focusing on the key experiments that explain fish oil mechanisms of action.

\section{Distinct effects of EPA and DHA}

Fish oil contains the two chemical species EPA and DHA, which are similar in terms of functional groups but different in terms of carbon backbone length and degree of unsaturation. EPA has 20 carbon atoms and 5 double bonds (20:5) while DHA has a longer chain of 22 carbon atoms and 6 double bonds (22:6). The higher degree of unsaturation in DHA probably yields increased proton selectivity and conductance by increasing the permeability of diphytanoylphosphatidylcholine black lipid membranes [18]. These differences in structure produce much different effects on inflammation, blood pressure and heart rate, endothelial function, atherosclerosis and post-myocardial infarction effects on collagen deposition.

\subsection{Inflammation}

Obesity-mediated low-grade chronic systemic inflammation contributes to the development of type 2 diabetes and cardiovascular disease [22]. The factor that has contributed to the overweight and obese populations in the US has been the increased consumption of linoelic and essential fatty acids [23]. Linoleic acid-enriched soybean oil consumption has increased from 0.006 to $7.38 \%$ during the twentieth century. During this same period, linoleic acid content in breast milk has increased from $6-7 \%$ to $15-16 \%$ of total fatty acid composition. Adipose tissue linoleic acid content has increased from 6\% in 1960 to $18 \%$ in 1986 [24]. While clinical studies have not been able to directly link obesity to an increased intake of only linoleic acid due to the complex composition of the diets used in those studies, studies in rodents clearly indicate that chronic consumption of a linoleic acidenriched n-6 fatty acid diet leads to obesity [25-27].

Replacement of n-6 fatty acids with n-3 LCPUFA prevents the progression of obesity in high-fat-fed rats [28]. Alvheim et al. showed that increased consumption of linoleic acid in C57BL/6J mice enhanced arachidonic acid levels, which stimulated endocannabinoids 2arachidonoylglycerol and anandamide synthesis. These products stimulate cannabinoid receptors to modulate central and peripheral responses, which stimulate appetite, increase food intake, activate fat storage pathways, promote adipocyte inflammation and downregulate catabolism. All of these combined functions result in adipose accumulation. Simultaneous dietary supplementation of EPA and DHA decreases the obesogenic effects of linoleic acid [27,29]. Oh et al. showed that the G protein-coupled receptor (GPR) 120 is a functional receptor that mediates potent insulin-sensitizing and anti-diabetic effects to reduce macrophage-induced tissue inflammation in mice [30]. A high-fat diet stimulated 
production of the M1 inflammatory genes interleukin (IL)-6, tumor necrosis factor (TNF)-a, monocyte chemotactic protein-1, IL-1 $\beta$, inducible nitric oxide synthase and CD11c in both wild-type (WT) and GPR null adipose tissue. Interestingly, n-3 fatty acid supplementation reduced inflammatory genes only in WT not GPR null mice. Similarly, the M2 antiinflammatory genes, arginase 1 , IL-10, macrophage galactose $N$-acetyl-galactosaminespecific lectin 1, Ym-1, Clec7a and macrophage mannose receptor were all increased by n-3 fatty acids in WT, but not in GPR120 null, adipose tissue. As GPR120 is highly expressed in pro-inflammatory M1 (but not M2) macrophages, this receptor probably serves as an n-3 fatty acid receptor to inhibit both the toll-like receptor (TLR)-2/3/4 and the TNF-astimulated responses to induce insulin sensitization [30].

The pro-inflammatory markers IL-6, C-reactive protein (CRP) and TNF-a are inversely correlated with levels of n-3 fatty acids in plasma as well as in erythrocytes, suggesting that the cardioprotective effects of fish oil supplementation may be through inhibiting these mediators [31-36]. Bouwens et al. demonstrated that fish oil decreased the expression of NF- $\kappa \mathrm{B}$ target genes, pro-inflammatory cytokines and eicosanoid synthesis genes in peripheral blood mononuclear cells [37]. DHA, but not EPA, reduced serum anti-doublestranded DNA antibodies and IgG deposition in kidneys. DHA also lowered lipopolysaccharide-mediated increases in serum IL-18 levels, as well as reduced caspase-1dependent cleavage of pro-IL-18 to mature IL-18 in the kidneys [38]. In addition, DHA dramatically extended both the median and the maximal life span of (NZBXNZW)F1 mixed background mice, while EPA had only a marginal effect on median and maximal life span of lupus-prone mice [38]. Mori et al. showed that urinary F2-isoprostanes were reduced 19\% by EPA and $20 \%$ by DHA, with no changes in CRP, IL- 6 or TNF-a levels [39]. The exact mechanism of how anti-inflammatory properties of DHA could translate to increased life span, therefore, requires additional investigation.

\subsection{Blood pressure and heart rate}

The third NHANES indicates that uncontrolled and untreated hypertension strongly associated with increased risk of total and cardiovascular mortality [40]. Law et al. demonstrated that reducing blood pressure decreased the overall mortality risk by $22 \%$ and reduced the risk of stroke by $41 \%$ [41]. Numerous epidemiological and interventional studies in patients with previous myocardial infarction have demonstrated a hypotensive role of fish oils [42]. Morris and co-workers showed that fish oil not only reduced blood pressure but also benefited patients with atherosclerosis or hypercholesterolemia [43].

Only a few human studies, however, have segregated the distinct effect of EPA and DHA on blood pressure [44-46]. Mori and his colleagues first established the differential effects of purified EPA and DHA on forearm vascular reactivity in overweight hyperlipidemic men. They showed that DHA, but not EPA, enhanced vasodilation and attenuated constrictor responses in the forearm microcirculation [47]. DHA (4 g/d) given for 6 weeks reduced $24 \mathrm{~h}$ systolic and diastolic blood pressures in hyperlipidemic male patients, while EPA had no effect (Figure 1) [39,47,48]. Woodman et al. showed that $4 \mathrm{~g} / \mathrm{d}$ of EPA or DHA both improved lipid levels, but both also showed adverse effects on short-term glycemic control, in hypertensive diabetic patients [44]. Heart rates were not affected in either group. Low doses of DHA from algal sources $(0.7 \mathrm{~g} / \mathrm{d})$ have also been shown to decrease diastolic blood pressure in healthy subjects, indicating that DHA from vegan sources is as effective as DHA from fish oil [49]. These studies indicate that DHA is more favorable in lowering blood pressure as well as improving vascular function. 


\subsection{Improved endothelial function}

The endothelium regulates vascular structure and tone, and exerts anticoagulant, antiplatelet and fibrinolytic properties [50]. Vascular endothelium dysfunction stimulates the development of atherosclerosis. Endothelial dysfunction stimulates leukocyte adhesion and extravasation [51]. Vascular tone is maintained by numerous dilator and constrictor substances. Nitric oxide is a major vasodilator substance released by the endothelium, while endothelin and angiotensin II are the major vasoconstrictor substances [50,51].

The pro-inflammatory cytokines IL-1, IL-4, tumor necrosis factor-a or bacterial endotoxin decreased vascular cell adhesion molecule 1 (VCAM-1), intercellular adhesion molecule 1 (ICAM-1) and E-selectin expression in cultured human endothelial cells, and DHA (10 $\mu \mathrm{mol} / \mathrm{l})$ suppressed this effect [52]. Omura et al. demonstrated that EPA $(30$ and $60 \mu \mathrm{M})$ improved NO production by activating eNOS through the $\mathrm{Ca}^{2+} /$ calmodulin system in bovine endothelial cells. EPA stimulated the translocation of endothelial nitric oxide synthase into the cytosol and its dissociation from caveolin, which prevented its inhibition [53]. By contrast, neither the EPA metabolite docosapentaenoic acid nor DHA stimulated nitric oxide production in endothelial cells [53].

Endothelial function improved following EPA or DHA feeding in both animal models [54,55] and humans [56]. Long-term supplementation of fish oil (2 weeks to 8 months) improved endothelium-dependent vasodilation, prevented vasoconstriction or increased exercise-induced blood flow [33,57-60]. Engler et al. showed that DHA (1.2 g/d for 6 weeks) improved endothelium-dependent flow-mediated dilation in hyperlipidemic children [61]. The comparative vasodilatory effects of high doses of EPA and DHA (4 g/d for 6 weeks) in overweight mildly hyperlipidemic males $(n=56)$ showed that DHA, but not EPA, decreased the vasoconstrictive responses to norepinephrine and increased the vasodilatory responses to acetylcholine [47]. By contrast, Okumura et al. showed that EPA supplementation (1.8 g/d for 3 months) improved endothelium-dependent forearm blood flow response in untreated hypertriglyceridemic male subjects [62]. Dietary supplementation of DHA ( $3 \mathrm{~g} / \mathrm{d}$, for $90 \mathrm{~d}$ ) in hypertriglyceridemic men did not alter the circulating levels of soluble ICAM-1, soluble VCAM-1 and E-selectin [63]. Importantly, the majority markers of inflammation such as CRP, IL-6 and granulocyte monocyte-colony stimulating factor are reduced in hypertrigly-ceridemic men [63]. Currently, only a limited number of studies have been performed, which prevents us from being able to draw conclusions regarding the differing effects of EPA and DHA on endothelium-dependent vasodilation.

\subsection{Atherosclerosis}

Atherosclerosis is the thickening of the arterial wall as a result of the accumulation of the lipid components cholesterol and triglycerides. The formation of plaques causes artery narrowing, as well as decreasing vessel flexibility and increasing blood flow resistance. The formation of plaques in arteries of the heart, lungs or brain can lead to myocardial infarction, pulmonary embolism or stroke [64]. In the pathological environment of atherosclerosis, endothelial cells and macrophages in the arterial wall release inflammatory substances, cytokines and growth factors $[65,66]$.

Fish oil modulates plasma concentrations of lipids, inflammatory markers, adhesion molecules and lipid peroxidation products that reduce plaque formation, platelet aggregation and thrombosis. Fish oil intake reduces the risk of atherosclerosis [67-69]. Recent literature has focused on the prominent use of DHA to prevent coronary artery disease [70,71], Both EPA and DHA lower triglycerides. DHA, but not EPA, increases both HDL-C and LDL-C (Table 1) $[46,72,73]$. Satoh et al. demonstrated that EPA-enriched capsules (of highly purified $>98 \%$ EPA ethyl ester) significantly reduced serum small-density LDL and CRP in 
patients with metabolic syndrome [74]. Amarin Inc., has developed a high EPA-containing product, is in the FDA drug approval process. This EPA-enriched product reduced LDL-C levels and also reduced major coronary events by $18 \%$ (compared with a $1.7 \%$ reduction in the control group) [75,76].

\subsection{Reduced collagen deposition}

In the myocardium, cardiac fibroblasts are the main source of extracellular matrix proteins, including collagen. Following stress or injury, profibrotic cytokines secreted primarily by leukocytes stimulate fibroblast proliferation and transformation into myofibroblasts. Myofibroblasts contribute to excessive collagen deposition, which increases ventricular wall stiffness and compromises filling. This impaired diastolic dysfunction can ultimately result in congestive heart failure [77,78]. Transforming growth factor (TGF)- $\beta 1$, a crucial profibrotic cytokine, promotes cardiac fibroblast phenotype differentiation and collagen accumulation and also inhibits collagen degradation [79,80]. The cyclic GMP(cGMP)proteinase kinase G (PKG) inhibits TGF- $\beta 1$-dependent nuclear translocation of phosphoSmad3 by PKG-mediated phosphorylation of the MH2 domain sites of Smad3 to block profibrotic response [81].

In a transverse aortic constriction model, 4 weeks of pressure overload induced left ventricular dysfunction, cardiac fibroblast activation and myocardial fibrosis [82]. Dietary supplementation with fish oil prevented cardiac dysfunction and blocked fibroblast activation and collagen production. In vitro, both EPA and DHA inhibited fibroblast transformation, proliferation and collagen synthesis by suppressing phospho-Smad2/3 nuclear translocation, without affecting Smad2/3 phosphorylation levels. EPA and DHA exert counter-fibrotic effects, in part by activating the cGMP/PKG signaling pathway. Dietary supplementation with PUFAs inhibited perivascular fibrosis in a model of high human renin hypertension and inhibited cardiac fibrosis in diabetic spontaneously hypertensive rats $[83,84]$. Microarray and quantitative RT-PCR analysis showed that n-3 PUFAs down-regulated the expression of fibrotic and hypertrophic genes to prevent atrial fibrillation in a dog model of atrial cardiomyopathy [85]. Kitamura et al. also demonstrated that EPA attenuated atrial fibrosis and prevented atrial fibrillation-associated heart failure [86]. Most of the studies shown above examined the effect of fish oil, the combination of both EPA and DHA, on cardiac fibrosis. However, studies that compare the impact of EPA versus DHA on myocardial fibrosis are needed.

\section{EPA- and DHA-derived lipid mediators for post-MI inflammation resolution}

The molecular basis for anti-inflammatory action of n-3 PUFAs, using an unbiased LC-MS/ MS-based technology and informatics approach, was devised to identify novel mediators generated from n-3 PUFAs precursors in response to acute injury. Using this approach, EPA and DHA were both found to be enzymatically converted into novel potent lipid mediators termed resolution phase interaction products (resolvins) [87,88]. Resolvins are a new distinct family of lipid mediators generated from n-3 PUFAs during injury resolution. Importantly, biosynthesis of resolvins gives rise to stereospecific local mediators that have potent actions and activate specific receptors.

In the presence of aspirin, both EPA and DHA undergo a series of metabolic transformations that involve cyclooxygenase and 5-lipoxygenase. E-series resolvins are produced from EPA and D-series resolvins and neuroprotectin D1 are produced from DHA. A major function of these metabolites is the resolution of inflammation. EPA- and DHA-derived metabolites exhibit similarities in anti-inflammatory actions, but are responsible for different mechanism 
of action and therapeutic effects in various processes in cardiovascular health and disease. For example, both resolvin E1 and resolvin D1 decrease the expression of IL-8, TNF-a, VCAM-1 and monocyte chemotactic protein-1 by endothelial cells and reduce leukocyte endothelial transmigration [89]. Interestingly, only the DHA-derived compound resolvin D1 decreased prostacyclin production in endothelial cells [89].

\section{Potential DHA derivatives for metabolic and cardiovascular disease}

Rossmeisl et al. designed a classical study to evaluate the ability of DHA derivatives to prevent or reverse obesity and glucose intolerance in high-fat-fed mice [90]. In this study, four different DHA derivatives (a-methyl DHA ethyl ester; a-ethyl DHA ethyl ester; a,a-dimethyl DHA ethyl ester; and a-thioethyl DHA ethyl ester) were screened for their effects on body weight and adiposity (Table 2). Out of these four different DHA derivatives, a-ethyl DHA ethyl ester-fed mice reduced food intake and the feeding efficiency by about $70 \%$. Moreover, the weight of subcutaneous and epididymal white adipose tissue is decreased by 73 and $42 \%$, respectively. The a-ethyl DHA ethyl ester is a promising DHA derivative in the treatment of obesity and associated metabolic disturbances. Interestingly, the reduced adipocyte hypertrophy observed in a-ethyl DHA ethyl ester-fed mice was accompanied by reduced macrophage infiltration. Important systemic markers of lipid metabolism, such as triglycerides, non-esterified fatty acids and cholesterol, are also decreased by feeding aethyl DHA ethyl ester in mice [90]. Based on these findings, a-ethyl DHA ethyl ester is a viable candidate for a nutrition-based drug discovery program for the development of naturally occurring n-3 fatty acid derivatives. DHA derivatives could qualify as a novel drug for the treatment of obesity, dyslipidemia, insulin resistance and cardiotoxicity. Tian et al. discovered the formation of DHA-derived $14 S, 21 R$-dihydroxydocosa-4Z,7Z,10Z,12E, 16Z, 19Z-hexaenoic acid (14S,21R-diHDHA) in $d b / d b$ diabetic mice. Furthermore, exogenous treatment of $14 S, 21 R$-diHDHA in cutaneous wounds counteracted the diabetic impairment on healing, angiogenesis and associated functions of mesenchymal stem cells in cutaneous excisional wound healing [91]. Morin et al. determined the effects of the DHA monoglyceride derivative CRBM-0244 on overreactivity and inflammation in TNF-atreated human bronchi. CRBM-0244 is synthesized from highly purified DHA attached to a monoglycerol in the sn-1 position using ethyl docosahexaenoate as the starting material. This DHA mono-glyceride derivative has potent anti-inflammatory effects and prevented the degradation of I $\kappa-\mathrm{B} a$ and subsequent nuclear translocation of the p65 NF- $\kappa \mathrm{B}$ subunit triggered by TNF-a stimulation. Furthermore, DHA monoglyceride derivative CRBM-0244 reduced airway inflammation in ovalbumin-sensitized lung tissue in guinea pig [92]. Hichami et al. synthesized and evaluated the mechanism of action of DAG-containing DHA-1-stearoyl-2-docosahexaenoyl-sn-glycerol in the modulation of the responsiveness of guinea pig airway smooth muscle and increase airway tension [93]. Yamamoto and Itoh synthesized more than 25 derivatives of DHA and tested these derivatives in Cos cells (Table 2). These novel compounds such as 4-OH-DHA, 4-oxo-DHA, 5E-4-hydroxy-DHA and its keto derivatives need to be investigated in more detail $[94,95]$.

\section{Fish oil attenuates anthracycline-induced cardiotoxicity}

Doxorubicin, an anti-tumor anthracycline antibiotic, not only is widely used for the treatment of specific types of leukemia but can also induce cardiotoxicity. A single dose of doxorubicin $\left(20 \mathrm{mg} / \mathrm{kg}\right.$, i.p.) induces ventricular dysfunction in mice. TLR2 $2^{-/}$and TLR4 $4^{-1-}$ mice are protected from doxorubicin-induced cardiomyopathy [96,97]. Recently, DHA has been shown to control differentiation of acute myeloid leukemia cell line KG1 [98]. Adjuvant therapy, with fish oil, DHA-enriched products or with novel DHA derivatives, provides valid alternatives to prevent anthracycline-induced cardiotoxicity [99]. 


\section{Caution on adverse effects of fish oil}

Adverse effects of fish oil can occur but are rarely explained or highlighted. Fish oil can induce platelet dysfunction, resulting in increased bleeding. While fish oil acts as a blood thinning agent to prevent coronary artery blockage, excessive blood thinning can be detrimental. Watson and colleagues evaluated bleeding incidences in coronary artery disease patients receiving high-dose fish oil (mean dose $3.00 \pm 1.25 \mathrm{~g}$, DHA $1.125 \mathrm{~g}$ and EPA 1.395 $\mathrm{g}$ ), aspirin (mean dose $161 \pm 115 \mathrm{mg}$ ) and clopidogrel (mean dose $75 \mathrm{mg}$ ) and compared with controls treated with aspirin and clopidogrel alone. They concluded that high-dose fish oil was safe in combination with aspirin and clopidogrel and did not increase the risk of bleeding compared with aspirin and clopidogrel alone [100].

In the Prostate Cancer Prevention Trial, Brasky and co-workers showed that the patients with the highest percentage of DHA had 2.5 times the risk of developing aggressive, highgrade prostate cancer compared with men with the lowest DHA levels [101]. In agreement with this observation, DHA supplementation given to SMAD3 ${ }^{-/}$null mice not only reduced the symptoms in an inflammatory-like bowel disease model but also increased the risk for colon cancer [102].

\section{Conclusion}

The efficacy of fish oil to treat hyperlipidemia has been established. There is also compelling evidence that DHA and EPA show distinct pharmacological and therapeutic effects $[6,17,18,73]$. The current major focus is on the development of DHA derivatives for novel drug development for the treatment of metabolic syndrome and cardiovascular disease (Figure 2).

\section{Expert opinion}

Fish oil as a dietary supplement is consumed from a large array of products and by a wide variety of population groups ranging from newborns to the ageing community. Fish oil is most often consumed to prevent cardiovascular disease. The variations in response to fish oil seen over different studies may be due to the different sources, doses and duration of fish oil used, the test system evaluated, assay sensitivity, patient population and disease condition. The purity of the fish oil and the concentration of each fatty acid are important considerations for adequate study design. This may explain why some studies using fish oil in combination with vitamin $\mathrm{E}$ showed a synergistic antioxidant effect that should be further explored in the future. Many, if not most, studies using disease models are based on the use of a combination of EPA and DHA; however, EPA, DHA and their individual metabolites or derivatives stimulate distinct metabolic pathways that could be exploited in isolation for the treatment of chronic diseases.

In current drug discovery approaches, cardiovascular safety concerns continue to be a leading reason for drug failures during development, leading to product withdrawal. There have been a number of notable product withdrawals, including terfenadine, cisapride, rofecoxib and rosiglitazone (withdrawn from the European market and prescribed with warning in US). The failure rate of current drug discovery is substantially high, with one compound reaching the market for every 1000 compounds that are successful in vitro. A focused nutritional approach may allow us to reduce the failure rate of drug molecules, particularly for those compounds that originate from EPA and DHA derivatization or metabolism. The principal benefit to using a nutrition-based drug discovery program, in combination with current drug discovery approaches, is that EPA and DHA are biomolecules, as well as their derivatives, and may provide novel treatments for obesity, insulin resistance and diabetes. Pharmacokinetics and pharmacodynamics studies of EPA- 
and DHA-derived biomolecules will help to drive the field toward the successful translational application of novel biomolecules. Multidimensional cellular, molecular and lipidomic tools will need to be integrated with current LIPID MAPS databases in order to specifically dissect the pharmacological mechanisms in particular disease models. A major research focus on DHA derivatives to study the inter-relationship between obesity, metabolic syndrome and cardiovascular disease will enable us to identify and develop novel drugs for these syndromes.

Based on the differential effects of EPA and DHA, future perspectives and key experimental strategies should be focused on the successful development of novel biomolecules using nutrition-based drug discovery approaches. Although the AHA has recommended a diet rich in PUFA, future studies examining the effects of $n-6$ fatty acids versus EPA or DHA may help the AHA to refine the current statement [103]. Directive areas should be focused to combat the dramatic increase in $\mathrm{n}-6$ fatty acids in our current diet. The additional development of n-3 fatty acid (e.g., DHA)-derived biomolecules is needed, to compete with the deleterious effects of $\mathrm{n}-6$ fatty acid intake. The priority and comprehensive evaluation of novel EPA and DHA biomolecules based on a nutrition-based drug discovery will provide therapeutic tools for various diseases. The efficacy and safety of novel EPA and DHA derivatives will help to clarify dietary guidance on recommendations for EPA and DHA. Prioritizing the evaluation of EPA- and DHA-derived biomolecules based on structural and activity relationships will add novel molecules for the drug discovery arsenal to treat obesity and cardiovascular disease.

\section{Bibliography}

Papers of special note have been highlighted as either of interest $(\bullet)$ or of considerable interest $(\bullet)$ to readers.

1••. Bang HO, Dyerberg J, Nielsen AB. Plasma lipid and lipoprotein pattern in Greenlandic West-coast Eskimos. Lancet. 1971; 1(7710):1143-5. The first scientific description for the antihyperlipidemic effect of marine sourced nutrition. [PubMed: 4102857]

2. Dyerberg J, Bang HO. Lipid metabolism, atherogenesis, and haemostasis in Eskimos: the role of the prostaglandin-3 family. Haemostasis. 1979; 8(3-5):227-33. [PubMed: 511010]

3. Dyerberg J, Bang HO, Hjorne N. Fatty acid composition of the plasma lipids in Greenland Eskimos. Am J Clin Nutr. 1975; 28(9):958-66. [PubMed: 1163480]

4. Ruzickova J, Rossmeisl M, Prazak T, et al. Omega-3 PUFA of marine origin limit diet-induced obesity in mice by reducing cellularity of adipose tissue. Lipids. 2004; 39(12):1177-85. [PubMed: 15736913]

5. Rustan AC, Christiansen EN, Drevon CA. Serum lipids, hepatic glycerolipid metabolism and peroxisomal fatty acid oxidation in rats fed omega-3 and omega-6 fatty acids. Biochem J. 1992; 283(Pt 2):333-9. [PubMed: 1349473]

6••. Mozaffarian D, Wu JH. (n-3) Fatty Acids and Cardiovascular Health: Are Effects of EPA and DHA Shared or Complementary? J Nutr. 2012; 142(3):614S-25S. A description of EPA and DHA differential pharmacological and biochemical properties in different test systems. [PubMed: 22279134]

7. Bays HE. Safety considerations with omega-3 fatty acid therapy. Am J Cardiol. 2007; 99(6A):35C$43 \mathrm{C}$.

8. Fassett RG, Gobe GC, Peake JM, Coombes JS. Omega-3 polyunsaturated fatty acids in the treatment of kidney disease. Am J Kidney Dis. 2010; 56(4):728-42. [PubMed: 20493605]

9. Fernandes G, Bhattacharya A, Rahman M, et al. Effects of n-3 fatty acids on autoimmunity and osteoporosis. Front Biosci. 2008; 13:4015-20. [PubMed: 18508495]

10. Bazan NG, Molina MF, Gordon WC. Docosahexaenoic acid signalolipidomics in nutrition: significance in aging, neuroinflammation, macular degeneration, Alzheimer's, and other neurodegenerative diseases. Annu Rev Nutr. 2011; 31:321-51. [PubMed: 21756134] 
11. Dietary supplementation with n-3 polyunsaturated fatty acids and vitamin $\mathrm{E}$ after myocardial infarction: results of the GISSI-Prevenzione Investigators (Gruppo Italianoper lo Studio della Sopravvivenza nell'Infarto Miocardico). Lancet. 1999; 354(9177):447-55. [PubMed: 10465168]

12•. Mozaffarian D, Wu JH. Omega-3 fatty acids and cardiovascular disease: effects on risk factors, molecular pathways, and clinical events. J Am Coll Cardiol. 2011; 58(20):2047-67. This review provides evidence that omega-3 fatty acid intake reduces the risk of cardiac death. [PubMed: 22051327]

13. Kromhout D, Bosschieter EB, de Lezenne Coulander C. The inverse relation between fish consumption and 20-year mortality from coronary heart disease. N Engl J Med. 1985; 312(19): 1205-9. [PubMed: 3990713]

14. Tavazzi L, Maggioni AP, Marchioli R, et al. Effect of n-3 polyunsaturated fatty acids in patients with chronic heart failure (the GISSI-HF trial): a randomised, double-blind, placebo-controlled trial. Lancet. 2008; 372(9645):1223-30. [PubMed: 18757090]

15. Lavie CJ, Milani RV, Mehra MR, Ventura HO. Omega-3 polyunsaturated fatty acids and cardiovascular diseases. J Am Coll Cardiol. 2009; 54(7):585-94. [PubMed: 19660687]

16. Kwak SM, Myung SK, Lee YJ, Seo HG. Efficacy of omega-3 fatty acid supplements (eicosapentaenoic acid and docosahexaenoic acid) in the secondary prevention of cardiovascular disease: a meta-analysis of randomized, double-blind, Placebo-controlled trials. Arch Intern Med. 2012 in press. 10.1001/archinternmed.2012.262

17••. Cottin SC, Sanders TA, Hall WL. The differential effects of EPA and DHA on cardiovascular risk factors. Proc Nutr Soc. 2011; 70(2):215-31. This review provides clear evidence on therapeutic utility of consuming either EPA or DHA. [PubMed: 21349231]

18••. Gorjao R, Azevedo-Martins AK, Rodrigues HG, et al. Comparative effects of DHA and EPA on cell function. Pharmacol Ther. 2009; 122(1):56-64. This review summarizes the known distinct effects of EPA and DHA on cell function. [PubMed: 19318040]

19. Flegal KM, Carroll MD, Kit BK, Ogden CL. Prevalence of obesity and trends in the distribution of body mass index among US adults, 1999-2010. JAMA. 2012 in press. 10.1001/jama.2012.39

20. Hotamisligil GS, Erbay E. Nutrient sensing and inflammation in metabolic diseases. Nat Rev Immunol. 2008; 8(12):923-34. [PubMed: 19029988]

21. Gonzalez-Periz A, Horrillo R, Ferre N, et al. Obesity-induced insulin resistance and hepatic steatosis are alleviated by omega-3 fatty acids: a role for resolvins and protectins. Faseb J. 2009; 23(6):1946-57. [PubMed: 19211925]

22. Poirier P, Giles TD, Bray GA, et al. Obesity and cardiovascular disease: pathophysiology, evaluation, and effect of weight loss: an update of the 1997 American heart association scientific statement on obesity and heart disease from the obesity committee of the council on nutrition, physical activity, and metabolism. Circulation. 2006; 113(6):898-918. [PubMed: 16380542]

23. Ailhaud G, Guesnet P, Cunnane SC. An emerging risk factor for obesity: does disequilibrium of polyunsaturated fatty acid metabolism contribute to excessive adipose tissue development? $\mathrm{Br} \mathrm{J}$ Nutr. 2008; 100(3):461-70. [PubMed: 18307824]

24••. Blasbalg TL, Hibbeln JR, Ramsden CE, et al. Changes in consumption of omega-3 and omega-6 fatty acids in the United States during the 20th century. Am J Clin Nutr. 2011; 93(5):950-62. The first comprehensive description of increased linoleic acid intake in the twentieth century. [PubMed: 21367944]

25. Halade GV, Rahman MM, Williams PJ, Fernandes G. High fat diet-induced animal model of ageassociated obesity and osteoporosis. J Nutr Biochem. 2010; 21:332-7. [PubMed: 19423318]

26•. Halade GV, El Jamali A, Williams PJ, et al. Obesity-mediated inflammatory microenvironment stimulates osteoclastogenesis and bone loss in mice. Exp Gerontol. 2011; 46(1):43-52. Provides evidence in rodents that chronic consumption of n- 6 fatty acids leads to obesity. [PubMed: 20923699]

27. Alvheim AR, Malde MK, Osei-Hyiaman D, et al. Dietary Linoleic Acid Elevates Endogenous 2AG and Anandamide and Induces Obesity. Obesity (Silver Spring). 2012 in press. 10.1038/oby. 2012.38

28. Storlien LH, Kraegen EW, Chisholm DJ, et al. Fish oil prevents insulin resistance induced by highfat feeding in rats. Science. 1987; 237(4817):885-8. [PubMed: 3303333] 
29. Halade GV, Jin YF, Lindsey ML. Roles of saturated vs. polyunsaturated fat in heart failure survival: not all fats are created equal. Cardiovasc Res. 2012; 93(1):4-5. [PubMed: 22068160]

30. Oh DY, Talukdar S, Bae EJ, et al. GPR120 is an omega-3 fatty acid receptor mediating potent antiinflammatory and insulin-sensitizing effects. Cell. 2010; 142(5):687-98. [PubMed: 20813258]

31. Farzaneh-Far R, Harris WS, Garg S, et al. Inverse association of erythrocyte n-3 fatty acid levels with inflammatory biomarkers in patients with stable coronary artery disease: the heart and soul study. Atherosclerosis. 2009; 205(2):538-43. [PubMed: 19185299]

32. Ferrucci L, Cherubini A, Bandinelli S, et al. Relationship of plasma polyunsaturated fatty acids to circulating inflammatory markers. J Clin Endocrinol Metab. 2006; 91(2):439-46. [PubMed: 16234304]

33. Rizza S, Tesauro M, Cardillo C, et al. Fish oil supplementation improves endothelial function in normoglycemic offspring of patients with type 2 diabetes. Atherosclerosis. 2009; 206(2):569-74. [PubMed: 19394939]

34. Damsgaard CT, Lauritzen L, Calder PC, et al. Reduced ex vivo interleukin-6 production by dietary fish oil is not modified by linoleic acid intake in healthy men. J Nutr. 2009; 139(7):1410-14. [PubMed: 19494025]

35. Trebble T, Arden NK, Stroud MA, et al. Inhibition of tumour necrosis factor-alpha and interleukin 6 production by mononuclear cells following dietary fish-oil supplementation in healthy men and response to antioxidant co-supplementation. Br J Nutr. 2003; 90(2):405-12. [PubMed: 12908901]

36. Caughey GE, Mantzioris E, Gibson RA, et al. The effect on human tumor necrosis factor alpha and interleukin 1 beta production of diets enriched in n-3 fatty acids from vegetable oil or fish oil. Am J Clin Nutr. 1996; 63(1):116-22. [PubMed: 8604658]

37. Bouwens M, van de Rest O, Dellschaft N, et al. Fish-oil supplementation induces antiinflammatory gene expression profiles in human blood mononuclear cells. Am J Clin Nutr. 2009; 90(2):415-24. [PubMed: 19515734]

38•. Halade GV, Rahman MM, Bhattacharya A, et al. Docosahexaenoic acid-enriched fish oil attenuates kidney disease and prolongs median and maximal life span of autoimmune lupusprone mice. J Immunol. 2010; 184:5280-5286. Describes the segregated effects of EPA and DHA on life span. [PubMed: 20368275]

39. Mori TA, Woodman RJ, Burke V, et al. Effect of eicosapentaenoic acid and docosahexaenoic acid on oxidative stress and inflammatory markers in treated-hypertensive type 2 diabetic subjects. Free Radic Biol Med. 2003; 35(7):772-81. [PubMed: 14583341]

40. Gu Q, Dillon CF, Burt VL, Gillum RF. Association of hypertension treatment and control with allcause and cardiovascular disease mortality among US adults with hypertension. Am J Hypertens. 2010; 23(1):38-45. [PubMed: 19851295]

41. Law MR, Morris JK, Wald NJ. Use of blood pressure lowering drugs in the prevention of cardiovascular disease: meta-analysis of 147 randomised trials in the context of expectations from prospective epidemiological studies. BMJ. 2009; 338:b1665. [PubMed: 19454737]

42. Mori TA. Omega-3 fatty acids and hypertension in humans. Clin Exp Pharmacol Physiol. 2006; 33(9):842-6. [PubMed: 16922818]

43. Morris MC, Sacks F, Rosner B. Does fish oil lower blood pressure? a meta-analysis of controlled trials. Circulation. 1993; 88(2):523-33. [PubMed: 8339414]

44. Woodman RJ, Mori TA, Burke V, et al. Effects of purified eicosapentaenoic and docosahexaenoic acids on glycemic control, blood pressure, and serum lipids in type 2 diabetic patients with treated hypertension. Am J Clin Nutr. 2002; 76(5):1007-15. [PubMed: 12399272]

45. Nestel P, Shige H, Pomeroy S, et al. The n-3 fatty acids eicosapentaenoic acid and docosahexaenoic acid increase systemic arterial compliance in humans. Am J Clin Nutr. 2002; 76(2):326-30. [PubMed: 12145002]

46. Grimsgaard S, Bonaa KH, Hansen JB, Myhre ES. Effects of highly purified eicosapentaenoic acid and docosahexaenoic acid on hemodynamics in humans. Am J Clin Nutr. 1998; 68(1):52-9. [PubMed: 9665096]

47••. Mori TA, Watts GF, Burke V, et al. Differential effects of eicosapentaenoic acid and docosahexaenoic acid on vascular reactivity of the forearm microcirculation in hyperlipidemic, 
overweight men. Circulation. 2000; 102(11):1264-9. Provides the first description of DHA effects on vascular reactivity, in comparison with EPA effects. [PubMed: 10982541]

48. Mori TA, Bao DQ, Burke V, et al. Docosahexaenoic acid but not eicosapentaenoic acid lowers ambulatory blood pressure and heart rate in humans. Hypertension. 1999; 34(2):253-60. [PubMed: 10454450]

49. Theobald HE, Goodall AH, Sattar N, et al. Low-dose docosahexaenoic acid lowers diastolic blood pressure in middle-aged men and women. J Nutr. 2007; 137(4):973-8. [PubMed: 17374663]

50. Davignon J, Ganz P. Role of endothelial dysfunction in atherosclerosis. Circulation. 2004; 109(23 Suppl 1):III27-32. [PubMed: 15198963]

51. Ross R. The pathogenesis of atherosclerosis: a perspective for the 1990s. Nature. 1993; 362(6423): 801-9. [PubMed: 8479518]

52. De Caterina R, Cybulsky MI, Clinton SK, et al. The omega-3 fatty acid docosahexaenoate reduces cytokine-induced expression of proatherogenic and proinflammatory proteins in human endothelial cells. Arterioscler Thromb. 1994; 14(11):1829-36. [PubMed: 7524649]

53. Omura M, Kobayashi S, Mizukami Y, et al. Eicosapentaenoic acid (EPA) induces Ca(2+)independent activation and translocation of endothelial nitric oxide synthase and endotheliumdependent vasorelaxation. FEBS Lett. 2001; 487(3):361-6. [PubMed: 11163359]

54. Mark G, Sanders TA. The influence of different amounts of $n-3$ polyunsaturated fatty acids on bleeding time and in vivo vascular reactivity. Br J Nutr. 1994; 71(1):43-52. [PubMed: 8312240]

55. Shimokawa H, Vanhoutte PM. Dietary cod-liver oil improves endothelium-dependent responses in hypercholesterolemic and atherosclerotic porcine coronary arteries. Circulation. 1988; 78(6):142130. [PubMed: 3191596]

56. Leeson CP, Mann A, Kattenhorn M, et al. Relationship between circulating n-3 fatty acid concentrations and endothelial function in early adulthood. Eur Heart J. 2002; 23(3):216-22. [PubMed: 11792136]

57. Chin JP, Gust AP, Nestel PJ, Dart AM. Marine oils dose-dependently inhibit vasoconstriction of forearm resistance vessels in humans. Hypertension. 1993; 21(1):22-8. [PubMed: 8418020]

58. Goodfellow J, Bellamy MF, Ramsey MW, et al. Dietary supplementation with marine omega-3 fatty acids improve systemic large artery endothelial function in subjects with hypercholesterolemia. J Am Coll Cardiol. 2000; 35(2):265-70. [PubMed: 10676668]

59. Tagawa T, Hirooka Y, Shimokawa H, et al. Long-term treatment with eicosapentaenoic acid improves exercise-induced vasodilation in patients with coronary artery disease. Hypertens Res. 2002; 25(6):823-9. [PubMed: 12484504]

60. Stirban A, Nandrean S, Gotting C, et al. Effects of n-3 fatty acids on macro- and microvascular function in subjects with type 2 diabetes mellitus. Am J Clin Nutr. 2010; 91(3):808-13. [PubMed: 20071644]

61. Engler MM, Engler MB, Malloy M, et al. Docosahexaenoic acid restores endothelial function in children with hyperlipidemia: results from the EARLY study. Int J Clin Pharmacol Ther. 2004; 42(12):672-9. [PubMed: 15624283]

62. Okumura T, Fujioka Y, Morimoto S, et al. Eicosapentaenoic acid improves endothelial function in hypertriglyceridemic subjects despite increased lipid oxidizability. Am J Med Sci. 2002; 324(5): 247-53. [PubMed: 12449445]

63•. Kelley DS, Siegel D, Fedor DM, et al. DHA supplementation decreases serum C-reactive protein and other markers of inflammation in hypertriglyceridemic men. J Nutr. 2009; 139(3):495-501. This paper describes DHA supplementation effects on chronological time points. [PubMed: 19158225]

64. Rader DJ, Daugherty A. Translating molecular discoveries into new therapies for atherosclerosis. Nature. 2008; 451(7181):904-13. [PubMed: 18288179]

65. Danesh J, Wheeler JG, Hirschfield GM, et al. C-reactive protein and other circulating markers of inflammation in the prediction of coronary heart disease. N Engl J Med. 2004; 350(14):1387-97. [PubMed: 15070788]

66. Burdge GC, Calder PC. Plasma cytokine response during the postprandial period: a potential causal process in vascular disease? Br J Nutr. 2005; 93(1):3-9. [PubMed: 15705218] 
67. Psota TL, Gebauer SK, Kris-Etherton P. Dietary omega-3 fatty acid intake and cardiovascular risk. Am J Cardiol. 2006; 98(4A):3i-18i.

68. Marik PE, Varon J. Omega-3 dietary supplements and the risk of cardiovascular events: a systematic review. Clin Cardiol. 2009; 32(7):365-72. [PubMed: 19609891]

69. Vrablik M, Prusikova M, Snejdrlova M, Zlatohlavek L. Omega-3 fatty acids and cardiovascular disease risk: do we understand the relationship? Physiol Res. 2009; 58(Suppl 1):S19-26. [PubMed: 19857032]

70. Ryan AS, Keske MA, Hoffman JP, Nelson EB. Clinical overview of algal-docosahexaenoic acid: effects on triglyceride levels and other cardiovascular risk factors. Am J Ther. 2009; 16(2):183-92. [PubMed: 19145206]

71. Holub BJ. Docosahexaenoic acid (DHA) and cardiovascular disease risk factors. Prostaglandins Leukot Essent Fatty Acids. 2009; 81(2-3):199-204. [PubMed: 19545988]

72. Mori TA, Burke V, Puddey IB, et al. Purified eicosapentaenoic and docosahexaenoic acids have differential effects on serum lipids and lipoproteins, LDL particle size, glucose, and insulin in mildly hyperlipidemic men. Am J Clin Nutr. 2000; 71(5):1085-94. [PubMed: 10799369]

73. Kelley DS, Adkins Y. Similarities and differences between the effects of EPA and DHA on markers of atherosclerosis in human subjects. Proc Nutr Soc. 2012; 71:1-10. in press. [PubMed: 22067138]

74. Satoh N, Shimatsu A, Kotani K, et al. Purified eicosapentaenoic acid reduces small dense LDL, remnant lipoprotein particles, and C-reactive protein in metabolic syndrome. Diabetes Care. 2007; 30(1):144-6. [PubMed: 17192349]

75. Yokoyama M, Origasa H, Matsuzaki M, et al. Effects of eicosapentaenoic acid on major coronary events in hypercholesterolaemic patients (JELIS): a randomised open-label, blinded endpoint analysis. Lancet. 2007; 369(9567):1090-8. [PubMed: 17398308]

76. Bays HE, Ballantyne CM, Kastelein JJ, et al. Eicosapentaenoic acid ethyl ester (AMR101) therapy in patients with very high triglyceride levels (from the Multi-center, plAcebo-controlled, Randomized, double-blINd, 12-week study with an open-label Extension [MARINE] trial). Am J Cardiol. 2011; 108(5):682-90. [PubMed: 21683321]

77. Brown RD, Ambler SK, Mitchell MD, Long CS. The cardiac fibroblast: therapeutic target in myocardial remodeling and failure. Annu Rev Pharmacol Toxicol. 2005; 45:657-87. [PubMed: 15822192]

78. Berk BC, Fujiwara K, Lehoux S. ECM remodeling in hypertensive heart disease. J Clin Invest. 2007; 117(3):568-75. [PubMed: 17332884]

79. Kuwahara F, Kai H, Tokuda K, et al. Transforming growth factor-beta function blocking prevents myocardial fibrosis and diastolic dysfunction in pressure-overloaded rats. Circulation. 2002; 106(1):130-5. [PubMed: 12093782]

80. Leask A. TGFbeta, cardiac fibroblasts, and the fibrotic response. Cardiovasc Res. 2007; 74(2): 207-12. [PubMed: 16919613]

81. Buxton IL, Duan D. Cyclic GMP/protein kinase G phosphorylation of Smad3 blocks transforming growth factor-beta-induced nuclear Smad translocation: a key antifibrogenic mechanism of atrial natriuretic peptide. Circ Res. 2008; 102(2):151-3. [PubMed: 18239144]

82. Chen J, Shearer GC, Chen Q, et al. Omega-3 fatty acids prevent pressure overload-induced cardiac fibrosis through activation of cyclic GMP/protein kinase $\mathrm{G}$ signaling in cardiac fibroblasts. Circulation. 2011; 123(6):584-93. [PubMed: 21282499]

83. Fischer R, Dechend R, Qadri F, et al. Dietary n-3 polyunsaturated fatty acids and direct renin inhibition improve electrical remodeling in a model of high human renin hypertension. Hypertension. 2008; 51(2):540-6. [PubMed: 18158339]

84. Medeiros FJ, Mothe CG, Aguila MB, Mandarim-de-Lacerda CA. Long-term intake of edible oils benefits blood pressure and myocardial structure in spontaneously hypertensive rat (SHR) and streptozotocin diabetic SHR. Prostaglandins Other Lipid Mediat. 2005; 78(1-4):231-48. [PubMed: 16303619]

85. Ramadeen A, Laurent G, dos Santos CC, et al. n-3 Polyunsaturated fatty acids alter expression of fibrotic and hypertrophic genes in a dog model of atrial cardiomyopathy. Heart Rhythm. 2010; 7(4):520-8. [PubMed: 20156610] 
86. Kitamura K, Shibata R, Tsuji Y, et al. Eicosapentaenoic acid prevents atrial fibrillation associated with heart failure in a rabbit model. Am J Physiol Heart Circ Physiol. 2011; 300(5):H1814-21. [PubMed: 21335470]

87. Serhan CN, Clish CB, Brannon J, et al. Novel functional sets of lipid-derived mediators with antiinflammatory actions generated from omega-3 fatty acids via cyclooxygenase 2-nonsteroidal antiinflammatory drugs and transcellular processing. J Exp Med. 2000; 192(8):1197-204. [PubMed: 11034610]

88. Serhan CN, Hong S, Gronert K, et al. Resolvins: a family of bioactive products of omega-3 fatty acid transformation circuits initiated by aspirin treatment that counter proinflammation signals. J Exp Med. 2002; 196(8):1025-37. [PubMed: 12391014]

89. Tian H, Lu Y, Sherwood AM, et al. Resolvins E1 and D1 in choroid-retinal endothelial cells and leukocytes: biosynthesis and mechanisms of anti-inflammatory actions. Invest Ophthalmol Vis Sci. 2009; 50(8):3613-20. [PubMed: 19443724]

90••. Rossmeisl M, Jelenik T, Jilkova Z, et al. Prevention and reversal of obesity and glucose intolerance in mice by DHA derivatives. Obesity (Silver Spring). 2009; 17(5):1023-31. Describes the effect of four different DHA derivatives on obesity prevention and reversal. [PubMed: 19148125]

91. Tian H, Lu Y, Shah SP, Hong S. 14S,21R-dihydroxydocosahexaenoic acid remedies impaired healing and mesenchymal stem cell functions in diabetic wounds. J Biol Chem. 2011; 286(6): 4443-53. [PubMed: 21112969]

92. Morin C, Fortin S, Cantin AM, Rousseau E. Docosahexaenoic acid derivative prevents inflammation and hyperreactivity in lung: implication of PKC-Potentiated inhibitory protein for heterotrimeric myosin light chain phosphatase of $17 \mathrm{kD}$ in asthma. Am J Respir Cell Mol Biol. 2011; 45(2):366-75. [PubMed: 21057106]

93•. Hichami A, Morin C, Rousseau E, Khan NA. Diacylglycerol-containing docosahexaenoic acid in acyl chain modulates airway smooth muscle tone. Am J Respir Cell Mol Biol. 2005; 33(4):37886. Describes the application of synthetically modified DHA on airway smooth muscle tone. [PubMed: 15961724]

94. Yamamoto K, Itoh T, Abe D, et al. Identification of putative metabolites of docosahexaenoic acid as potent PPARgamma agonists and antidiabetic agents. Bioorg Med Chem Lett. 2005; 15(3):51722. [PubMed: 15664804]

95. Itoh T, Murota I, Yoshikai K, et al. Synthesis of docosahexaenoic acid derivatives designed as novel PPARgamma agonists and antidiabetic agents. Bioorg Med Chem. 2006; 14(1):98-108. [PubMed: 16198578]

96. Riad A, Bien S, Gratz M, et al. Toll-like receptor-4 deficiency attenuates doxorubicin-induced cardiomyopathy in mice. Eur J Heart Fail. 2008; 10(3):233-43. [PubMed: 18321777]

97. Nozaki N, Shishido T, Takeishi Y, Kubota I. Modulation of doxorubicin-induced cardiac dysfunction in toll-like receptor-2-knockout mice. Circulation. 2004; 110(18):2869-74. [PubMed: 15505089]

98. Yamagami T, Porada CD, Pardini RS, et al. Docosahexaenoic acid induces dose dependent cell death in an early undifferentiated subtype of acute myeloid leukemia cell line. Cancer Biol Ther. 2009; 8(4):331-7. [PubMed: 19197149]

99. Teng LL, Shao L, Zhao YT, et al. The beneficial effect of n-3 polyunsaturated fatty acids on doxorubicin-induced chronic heart failure in rats. J Int Med Res. 2010; 38(3):940-8. [PubMed: 20819430]

100. Watson PD, Joy PS, Nkonde C, et al. Comparison of bleeding complications with omega-3 fatty acids + aspirin + clopidogrel-versus-aspirin + clopidogrel in patients with cardiovascular disease. Am J Cardiol. 2009; 104(8):1052-4. [PubMed: 19801023]

101. Brasky TM, Till C, White E, et al. Serum phospholipid fatty acids and prostate cancer risk: results from the prostate cancer prevention trial. Am J Epidemiol. 2011; 173(12):1429-39. [PubMed: 21518693]

102. Woodworth HL, McCaskey SJ, Duriancik DM, et al. Dietary fish oil alters T lymphocyte cell populations and exacerbates disease in a mouse model of inflammatory colitis. Cancer Res. 2010; 70(20):7960-9. [PubMed: 20798218] 
103••. Harris WS, Mozaffarian D, Rimm E, et al. Omega-6 fatty acids and risk for cardiovascular disease: a science advisory from the American heart association nutrition subcommittee of the council on nutrition, physical activity, and metabolism; council on cardiovascular nursing; and council on epidemiology and prevention. Circulation. 2009; 119(6):902-7. Provides a comprehensive description of the advisory guidelines on the consumption of linoleic acid. [PubMed: 19171857]

104. Park Y, Harris W. EPA, but not DHA, decreases mean platelet volume in normal subjects. Lipids. 2002; 37(10):941-6. [PubMed: 12530552]

105. Morin C, Fortin S, Rousseau E. 19,20-EpDPE, a bioactive CYP450 metabolite of DHA monoacyglyceride, decreases $\mathrm{Ca}$ (2) sensitivity in human pulmonary arteries. Am J Physiol Heart Circ Physiol. 2011; 301(4):H1311-18. [PubMed: 21821782] 


\section{Article highlights}

- Observational evidence suggested that seafood promotes health, which led to the development of fish oil as a dietary supplement. This eventually culminated in the FDA approval for concentrated fish oil as a drug for the treatment of hyperlipidemia.

- Fish oil is composed of two main constituents: eicosapentaenoic acid and docosahexaenoic acid, which are chemically different and possess distinct pharmacological and therapeutic potentials.

- Newly synthesized derivatives and endogenously discovered metabolites of DHA exhibit therapeutic utility for obesity, metabolic syndrome and cardiovascular disease.

- Novel DHA derivatives and metabolites have high drug candidate potential, but more detailed investigations are needed for the successful translation of biomolecules developed from a nutrition-based drug discovery process into human use.

This box summarizes key points contained in the article. 


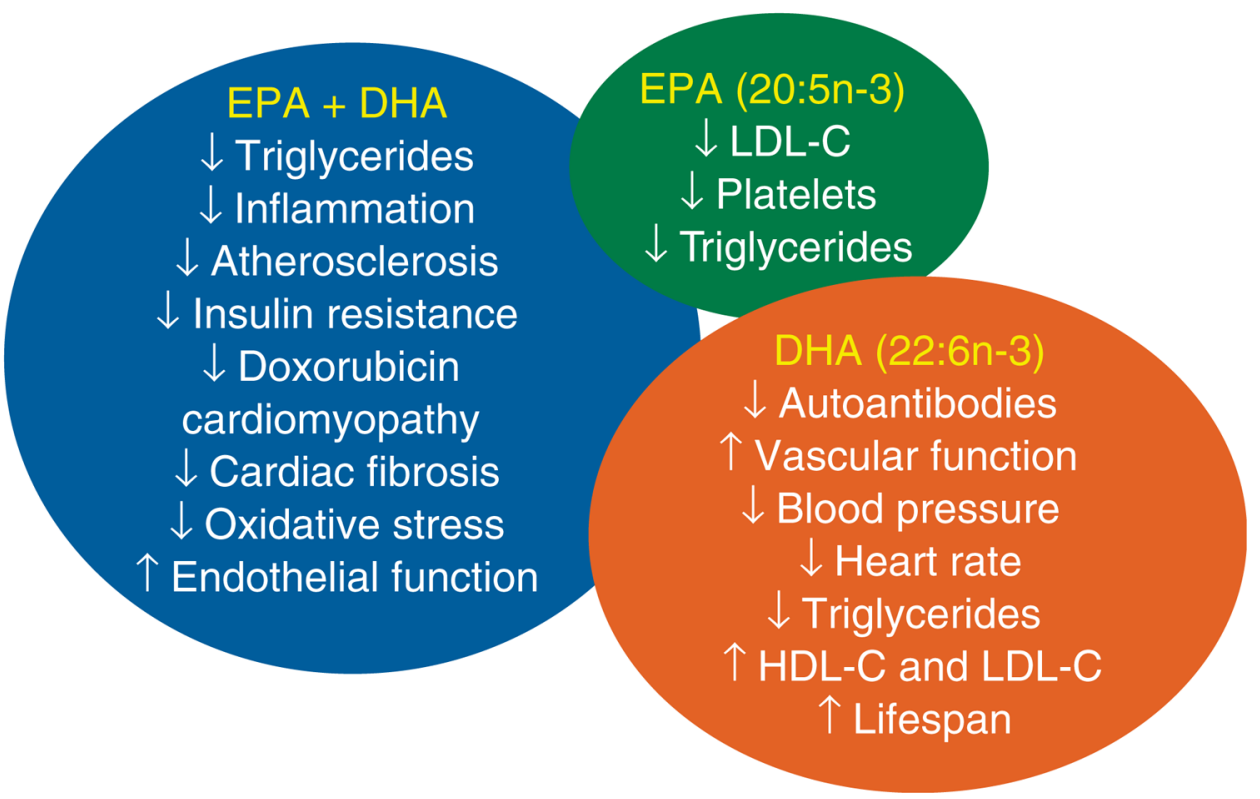

Figure 1. Summary of the known roles of eicosapentaenoic acid (EPA) + docosahexaenoic acid (DHA), compared with the differential roles of EPA and DHA in isolation EPA-specific effects are denoted in the green circle. DHA-specific effects are denoted in brown circle. Effects that are seen with the combination of EPA and DHA are denoted in the blue ellipse. 


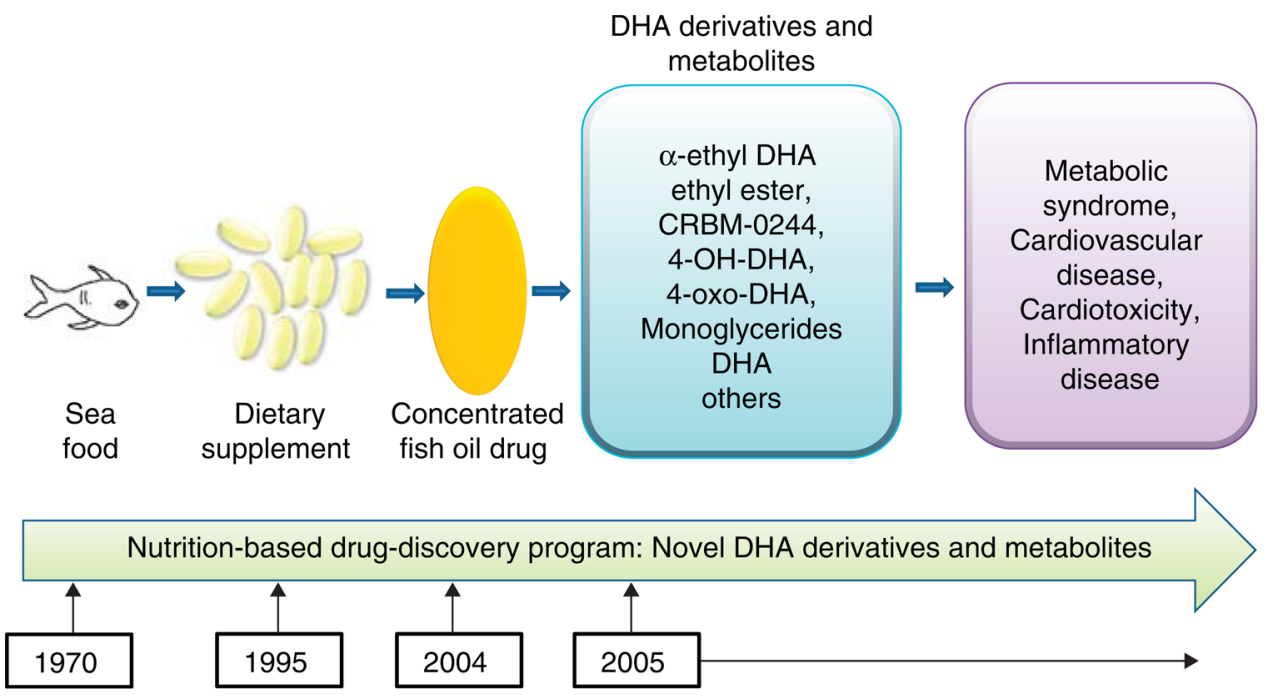

Figure 2. A nutrition-based fatty acid drug discovery program was used during the journey from observing the benefits of a seafood diet to the development of new docosahexaenoic acid (DHA)derived biomolecules for the prevention and treatment of metabolic syndrome, cardiovascular disease and inflammatory disease 


\section{Table 1}

Key mechanistic studies that elucidate the distinct effects of eicosapentaenoic acid (EPA) and docosahexaenoic acid (DHA) [6,39,42,47,63,72,74,104].

\begin{tabular}{lll}
\hline Clinical outcome/markers & EPA & DHA \\
\hline Blood pressure & N.S. & $\begin{array}{l}\downarrow \text { Blood pressure, } \downarrow \text { Heart rate, } \uparrow \text { Vascular } \\
\text { function }\end{array}$ \\
Platelet volume and numbers & $\begin{array}{l}\downarrow \text { platelet volume and } \uparrow \text { platelet } \\
\text { count }\end{array}$ & N.S. \\
Serum metabolites: TG, insulin, HDL cholesterol & $\downarrow$ TGs, $\uparrow$ Insulin & $\downarrow$ TGs, $\uparrow$ Insulin, $\uparrow$ HDL and HDL 2 cholesterol \\
High- and low-density cholesterol HDL-C and LDL-C & $\downarrow$ LDL-C & $\uparrow$ HDL-C, $\uparrow$ LDL-C \\
Oxidative stress & $\downarrow$ F2-isoprostanes & $\downarrow$ F2-isoprostanes \\
Inflammatory markers & $\downarrow$ TNF-a & $\downarrow$ CRP, $\downarrow$ IL-6, $\downarrow$ G-MCSF, $\downarrow$ TNF-a \\
\hline
\end{tabular}

This table was modified from [6] with permission of the American Society for Nutrition. 
Table 2

Docosahexaenoic acid (DHA) derivatives and metabolites that are currently in pipeline for screening for the treatment of various pharmacological and therapeutic targets [90-92,94,95,105].

\begin{tabular}{|c|c|c|c|}
\hline Year & Test system/animal model & Name of metabolite or derivative & Pharmacological effect \\
\hline 2011 & $\begin{array}{l}\text { U-46619 on human pulmonary } \\
\text { arteries }\end{array}$ & DHA monoacylglyceride induces 19, 20-epoxydocosapentaenoic acid & $\begin{array}{l}\uparrow \text { RhoA and } \downarrow \mathrm{Ca}^{2+} \\
\text { sensitivity }\end{array}$ \\
\hline 2011 & $\begin{array}{l}\text { Human bronchi and } \\
\text { ovalbumin-sensitized lung } \\
\text { tissue in guinea pig }\end{array}$ & DHA monoglyceride derivative CRBM-0244 & $\begin{array}{l}\downarrow \text { TNF- } a \text {-induced } \\
\text { inflammation, } \downarrow \text { NF- } \kappa \mathrm{B} \\
\text { and } \downarrow \text { COX-2 }\end{array}$ \\
\hline 2011 & Diabetic mice & $14 S, 21 R$-dihydroxydocosa-4Z,7Z,10Z,12E,16Z,19Z-hexaenoic acid ( $14 S, 21 R$-diHDHA) & $\begin{array}{l}\uparrow \text { wound healing and } \\
\text { angiogenesis }\end{array}$ \\
\hline 2009 & C57BL/6J Diet-induced obesity & a-ethyl DHA ethyl ester & $\begin{array}{l}\downarrow \text { Obesity, } \\
\downarrow \text { Macrophage } \\
\text { infiltration, } \downarrow \text { adipocyte } \\
\text { hypertrophy and } \downarrow \text { TGs, } \\
\text { NEFA and cholesterol }\end{array}$ \\
\hline 2006 & $\begin{array}{l}\text { Crystal structure ligand- } \\
\text { binding domain and Cos cells }\end{array}$ & 4-OH-DHA and 4-oxo-DHA out of 25 synthetic DHA derivatives & $\begin{array}{l}\text { Potent anti-diabetic } \\
\text { comparable with } \\
\text { pioglitazone }\end{array}$ \\
\hline 2005 & Cos-7 cells & 5E-4-hydroxy-DHA and its keto derivatives out of 19 DHA derivatives & $\begin{array}{l}\text { 5E-4-hydroxy-DHA } \\
\text { fourfold stronger than } \\
\text { pioglitazone } \\
\text { 4-keto derivative of } \\
\text { 5E-4-hydroxy- anti- } \\
\text { diabetic activity }\end{array}$ \\
\hline 2005 & $\begin{array}{l}\text { Airway smooth muscle (guinea } \\
\text { pig) }\end{array}$ & DAG-containing DHA-1-stearoyl-2-docosahexaenoyl-sn-glycerol (SDHG) & $\begin{array}{l}\mathrm{DAGs} \uparrow \mathrm{ASM} \\
\text { contraction } \\
\mathrm{SDHG} \uparrow \text { tension }\end{array}$ \\
\hline
\end{tabular}

